\title{
Hubungan Karakteristik dan Kecerdasan Spiritual Perawat dengan Pemenuhan Kebutuhan Layanan Spiritual Pasien Rawat Inap
}

\author{
The Relationship of Characteristics and Intelligence of Nursing \\ Spirituals with Fulfilling the Needs of Inpatient Spiritual Services
}

\author{
Nurherawati $^{(1)}$, Emma Rachmawati ${ }^{(1)}$, Mouhamad Bigwanto ${ }^{(1)}$ \\ ${ }^{(1)}$ Fakultas Ilmu - Ilmu Kesehatan, Universitas Muhammadiyah Prof Dr. Hamka Jakarta, Indonesia
}

Korespondensi Penulis: Nurherawati, Program Studi Kesehatan Masyarakat, Fakultas Ilmu - Ilmu Kesehatan Universitas Muhammadiyah Prof Dr. Hamka Jakarta

Email: nherawti@gmail.com

\begin{abstract}
ABSTRAK
Perawat dalam memenuhi kebutuhan layanan spiritual pada pasien dipengaruhi oleh salah satu faktor yaitu kecerdasan spiritual. Tujuan penelitian untuk mengetahui hubungan karakteristik dan kecerdasan spiritual perawat dengan pemenenuhan kebutuhan layanan spiritual pasien rawat inap di RSUD Banten Tahun 2019. Tempat dan waktu penelitian dilakukan di RSUD Banten pada bulan Juli-Agustus 2019. Jenis penelitian adalah kuantitatif dengan desain cross sectional. Menggunakan data primer melalui pengisian angket. Analisis data yang digunakan adalah analisis univariat dan bivariat dengan uji Chi-square. Populasi dan sampel menggunakan teknik total sampling berjumlah 71 perawat. Hasil penelitian menunjukkan responden yang melakukan pemenuhan kebutuhan layanan spiritual kurang baik sebanyak 37 responden $(52,1 \%)$. Hasil bivariat menunjukkan variabel yang berhubungan dengan pemenuhan kebutuhan layanan spiritual yaitu tingkat pendidikan ( $\mathrm{p}$ value $=0,039)$, lama kerja $(\mathrm{p}$ value $=0,042)$, dan kecerdasan spiritual perawat $(\mathrm{p}$ value $=0,022)$. Berdasarkan hasil penelitian disarankan perlu adanya pendampingan atau mentor khusus yang dilakukan oleh perawat senior kepada perawat junior (lama kerja $\leq 4$ tahun). Karena hasil penelitian membuktikan bahwa perawat yang memiliki lama kerja baru yang berpeluang melakukan pemenuhan kebutuhan layanan spiritual kurang baik pada pasien.
\end{abstract}

Kata Kunci : Perawat, Kecerdasan Spiritual, Kebutuhan Layanan Spiritual.

\begin{abstract}
Nurses in meeting spiritual service needs in patients are influenced by one of the factors namely spiritual intelligence. The purpose of the study was to determine the relationship between characteristics and nurse's spiritual intelligence by fulfilling the inpatient spiritual service needs in Banten Hospital in 2019. The study was conducted in Banten General Hospital in July-August 2019. This research was quantitative with a cross-sectional design by using a questionnaire as a primary data and using Chi-square test as the data analysis. The sample used all nurses in population with total sampling to 71 nurses. The results showed that respondents who fulfilled the needs of spiritual services were not as good as 37 respondents $(52.1 \%)$. Bivariate results showed variables related to meeting spiritual service needs, namely the level of education ( $p$ value $=0.039$ ), length of work ( $p$ value $=0.042$ ), and nurse spiritual intelligence ( $p$ value $=0.022$ ). Based on the results of this study it is suggested that there is a need for assistance or special mentors conducted by senior nurses to junior nurses (length of work $\leq 4$ years). Because the results of this research prove that nurses who have a new length of work who have the opportunity to meet the needs of spiritual services are not good for patients.
\end{abstract}

Keywords: Nurses, Spiritual Intelligence, Spiritual Service Needs. 


\section{PENDAHULUAN}

Rumah sakit sebagai penyedia pelayanan kesehatan merupakan suatu organisasi yang sangat kompleks, karena bergerak dalam bidang pelayanan jasa yang melibatkan berbagai kelompok profesi dengan latar belakang pendidikan dan kehidupannya, salah satunya profesi keperawatan yang merupakan bagian integral dari sistem kesehatan, dapat menjadi pendamping utama dokter dalam keberhasilan pelayanan kesehatan di pusat pelayanan kesehatan atau rumah sakit. Dikatakan utama karena peran dan tanggung jawab kedua profesi itu secara langsung berdampak pada hasil akhir pelayanan pasien. Namun kelompok keperawatan merupakan salah satu komponen dianggap sebagai kunci dari keberhasilan asuhan kesehatan di rumah sakit. Hal ini terjadi karena perawat harus selalu berada di samping pasien, sentuhan asuhan keperawatan telah dirasakan pasien sejak dia masuk rumah sakit, selama dirawat dan pada waktu pulang. Selain itu tenaga perawat juga sangat berperan penting untuk membantu kesembuhan pasien (Sumijatun, 2010).

Penelitian yang dilakukan oleh Merianti \& Andika (2016) bahwa perawat yang memiliki kecerdasan spiritual rendah berjumlah 11 orang, dimana 9 orang $(81,8 \%)$ diantaranya memiliki kempetensi yang rendah dalam pemberian asuhan spiritual, 2 lainnya $(18,2 \%)$ memiliki kompetensi yang tinggi dalam pemberian asuhan spiritual. Penelitian sebelumnya yang dilakukan oleh Alfiannur, dkk (2015) terkait tentang kecerdasan spiritual adalah responden yang memiliki kecerdasan spiritual tinggi berjumlah 18 responden $(36,7 \%)$ sedangkan responden yang memiliki kecerdasan spiritual sedang berjumlah 12 responden (40\%). Selain itu, penelitian yang dilakukan oleh Sidabutar (2016) bahwa penerapan aspek spiritualitas oleh perawat pada pasien ruang rawat inap di RS Islam Malahayati Medan terdapat $21(61,8 \%)$ masih kurang dan perawat yang mempunyai penerapan aspek spiritual baik sebanyak 13 (38,2\%). Hal ini didukung oleh teori yang mengatakan bahwa perawat sering menggunakan alasan tidak cukup waktu untuk menerapkan nilai spiritualitas yang dianut untuk kesehatan pasien (Potter \& Perry, 2005).

Berdasarkan hasil studi pendahuluan pada tanggal 28 Maret 2019 dan yang dilakukan pada 20 perawat di ruang rawat inap RSUD Banten menunjukan bahwa sebanyak 14 perawat mengalami kendala dalam memberikan layanan perawatan spiritual dan masih kurang optimalnya perawatan spiritual yang dilakukan oleh perawat. Hal ini dikarenakan bahwa komunikasi antara pasien dan perawat masih kurang, kurangnya motivasi perawat dalam memberikan asuhan perawatan spiritual serta adanya kendala perbedaan budaya pasien. Selain itu, perawat tidak membantu pasien untuk beribadah, tidak mengajarkan doa kepada pasien dan tidak mengingatkan waktu solat kepada pasien, karena perawat meyakini bahwa semua itu adalah tugas dari bagian bimbingan rohani.

Perawat juga mengatakan bahwa belum pernah mengikuti pelatihan perawatan spiritual dan belum adanya pelatihan tersebut di rumah sakit. Perawat juga belum pernah mengkaji secara detail terkait perawatan spiritual. Perawat mengetahui bahwa layanan spiritual sangat bermanfaat bagi pasien terutama proses penyembuhan, namun dalam implementasinya tidak semua perawat memberikan asuhan perawatan spiritual secara mandiri untuk pasien. Hal tersebut dikarenakan bahwa perawat belum mengikuti dan belum adanya pelatihan perawatan spiritual.

Berdasarkan hasil uraian permasalahan di atas, maka penulis bertujuan untuk meneliti terkait tentang hubungan karakteristik dan kecerdasan spiritual perawat dengan pemenuhan kebutuhan layanan spiritual pasien rawat inap di RSUD Banten.

\section{SUBYEK DAN METODE}

Penelitian ini merupakan penelitian kuantitatif dengan desain cross sectional. Penelitian ini terdiri dari variabel independen yaitu karakteristik perawat (jenis kelamin, usia, tingkat pendidikan, lama kerja), dan kecerdasan spiritual perawat. Sedangkan variabel dependen pada penelitian ini adalah pemenuhan kebutuhan layanan spiritual pasien. Lokasi penelitian ini dilakukan di RSUD Banten pada perawat di ruang rawat inap. Waktu pengambilan data dilakukan pada bulan Juli Tahun 2019. Populasi pada penelitian ini adalah seluruh perawat di ruang rawat inap RSUD Banten berjumlah 71 perawat dengan teknik pengambilan sampel menggunakan total sampling. Metode pengumpulan data menggunakan dua cara aitu pengumpulan data primer dengan cara pengisian angket yang diisi oleh responden. Sedangkan data sekunder didapatkan secara langsung dari RSUD Banten. 
analisis data yang digunakan analisis univariat dan bivariat dengan uji chi-square. Pada penelitian ini menggunakan uji chi-square dikarenakan penelitian ini dilakukan dalam waktu yang bersamaan.
HASIL

Hasil analisis univariat dan bivariat pada penelitian ini dapat dilihat pada tabel 1 dan 2 berikut:

Tabel 1. Hubungan Karaktersitik dan Kecerdasan Spiritual Perawat dengan Pemenuhan Kebutuhan Layanan Spiritual Pasien Rawat Inap di RSUD Banten Tahun 2019

\begin{tabular}{lccc}
\hline \multicolumn{1}{c}{ Variabel } & Kategorik & n & \% \\
\hline Jenis Kelamin & Laki - laki & 21 & 28,2 \\
& Perempuan & 50 & 71,8 \\
Usia & Muda & 29 & 40,8 \\
\multirow{2}{*}{ Tingkat Pendidikan } & Tua & 42 & 59,2 \\
& D3 & 32 & 45,1 \\
Lama Bekerja & S1/Lebih Tinggi & 39 & 54,9 \\
& Baru & 34 & 47,9 \\
Kecerdasan Spiritual perawat & lama & 37 & 52,1 \\
\multirow{2}{*}{ Pemenuhan kebutuhan layanan } & Rendah & 33 & 46,5 \\
spiritual & Tinggi & 38 & 53,5 \\
& Kurang Baik & 37 & 52,1 \\
& Baik & 34 & 47,9 \\
\hline
\end{tabular}

Tabel 2. Hubungan Karakteristik dan Kecerdasan Spiritual Perawat dengan Pemenuhan Kebutuhan Layanan Spiritual Pasien Rawat Inap di RSUD Banten Tahun 2019

\begin{tabular}{|c|c|c|c|c|c|c|c|c|}
\hline \multirow{3}{*}{ Variabel } & \multirow{2}{*}{\multicolumn{4}{|c|}{$\begin{array}{c}\text { Pemenuhan Kebutuhan } \\
\text { Lavanan Spiritual }\end{array}$}} & \multirow{2}{*}{\multicolumn{2}{|c|}{ Jumlah }} & \multirow{3}{*}{$\begin{array}{c}\text { PR } \\
(95 \% \mathrm{CI})\end{array}$} & \multirow{3}{*}{$\begin{array}{c}\mathrm{P} \\
\text { value }\end{array}$} \\
\hline & & & & & & & & \\
\hline & n & $\%$ & $\mathrm{n}$ & $\%$ & $\mathrm{n}$ & $\%$ & & \\
\hline \multicolumn{9}{|l|}{ Jenis kelamin } \\
\hline Laki-Laki & 9 & 45,0 & 11 & 55,0 & 20 & 100 & 0,820 & \multirow{2}{*}{0,452} \\
\hline Perempuan & 28 & 54,9 & 23 & 45,1 & 51 & 100 & $(0,475-1.413)$ & \\
\hline \multicolumn{9}{|l|}{ Usia } \\
\hline Muda & 12 & 41,4 & 17 & 58,6 & 29 & 100 & 0,695 & \multirow{2}{*}{0,132} \\
\hline Tua & 25 & 59,5 & 17 & 40,5 & 42 & 100 & $(0,422-1.146)$ & \\
\hline \multicolumn{9}{|l|}{ Tingkat } \\
\hline \multicolumn{9}{|l|}{ Pendidikan } \\
\hline D3 & 21 & 65,6 & 11 & 34,4 & 32 & 100 & 1.600 & \multirow{2}{*}{0,039} \\
\hline S1/Lebih Tinggi & 16 & 41,0 & 23 & 59,0 & 39 & 100 & $(1.018-2.514)$ & \\
\hline \multicolumn{9}{|l|}{ Lama Kerja } \\
\hline Baru $\leq 4$ Tahun & 22 & 64,7 & 12 & 35,3 & 34 & 100 & 1.596 & \multirow{2}{*}{0,042} \\
\hline Lama > 4Tahun & 15 & 40,5 & 22 & 59,5 & 37 & 100 & $(1.005-2.535)$ & \\
\hline \multirow{2}{*}{\multicolumn{9}{|c|}{$\begin{array}{l}\text { Kecerdasan } \\
\text { Spiritual perawat }\end{array}$}} \\
\hline & & & & & & & & \\
\hline Rendah & 22 & 66,7 & 11 & 33,3 & 33 & 100 & 1.689 & \multirow{2}{*}{0,022} \\
\hline Tinggi & 15 & 39,5 & 23 & 60,5 & 38 & 100 & $(1.064-2.680)$ & \\
\hline
\end{tabular}

Tabel 1 di atas menunjukkan bahwa mayoritas responden berjenis kelamin perempuan sebesar $51(71,8 \%)$, usia responden paling banyak pada usia tua sebesar $42(59,2 \%)$, tingkat pendidikan responden $\mathrm{S} 1 /$ lebih tinggi sebesar $39(54,9 \%)$, lama kerja responden ratarata lama kerja lama (>4tahun) sebesar 37 $(52,1 \%)$. Responden pada penelitian ini menunjukan bahwa rata-rata memiliki kecerdasan spiritual tinggi sebesar 38 (53,5\%), dan esponden yang melakukan pemenuhan kebutuhan layanan spiritual kurang baik sebesar $37(52,1 \%)$.

Adapun pada tabel 2 menunjukan bahwa variabel jenis kelamin yang melakukan pemenuhan kebutuhan layanan spiritual kurang 
baik yaitu pada jenis kelamin perempuan sebesar (54,9\%) dibandingkan dengan jenis kelamin laki-laki. Variabel usia yang melakukan pemenuhan kebutuhan layanan spiritual kurang baik yaitu pada usia tua sebesar $(59,5 \%)$ dibandingkan dengan usia muda. Variabel tingkat pendidikan yang melakukan pemenuhan kebutuhan layanan spiritual kurang baik yaitu pada tingkat pendidikan D3 sebesar $(65,6 \%)$ dibandingkan dengan tingkat pendidikan S1/lebih tinggi. Pada variabel lama kerja yang melakukan pemenuhan kebutuhan layanan spiritual kurang baik yaitu yang memiliki lama kerja baru $\leq 4$ tahun sebesar $(64,7 \%)$ dibandingkan dengan lama kerja lama $>4$ tahun. Kemudian pada variabel kecerdasan spiritual perawat yang melakukan pemenuhan kebutuhan layanan spiritual kurang baik yaitu pada kecerdasan spiritual perawat yang rendah sebesar $(66,7 \%)$ dibandingkan dengan perawat yang memiliki kecerdasan spiritual yang tinggi.

\section{DISKUSI}

Hasil penelitian ini menunjukan bahwa responden dengan jenis kelamin perempuan lebih banyak yaitu sebesar 28 (54,9\%). Hasil analisis uji chi-square menunjukan bahwa tidak ada hubungan antara jenis kelamin dengan pemenuhan kebutuhan layanan spiritual dengan nilai ( $\mathrm{p}$ value $=0,452)$. Sejalan dengan penelitian Riyadi (2007) bahwa tidak ada hubungan antara jenis kelamin perawat dengan kinerja perawat dalam memberikan pelayanan keperawatan pada pasien. Karena jenis kelamin baik perempuan maupun laki-laki sama sekali tidak memberikan pengaruh pada tinggi atau rendahnya suatu tingkat pemenuhan kebutuhan spiritual pada pasien (Primeilan, 2004). Namun berbeda dengan teori Potter \& Perry (2009) yang menunjukkan bahwa laki-laki cenderung mengkomunikasikan sesuatu secara langsung tanpa banyak pertimbangan dan melihat hubungan sebagai tugas saja, sedangkan perempuan cenderung lebih hati-hati dan teliti dalam melakukan penilaian terhadap sesuatu yang dianggap baik dan ataupun kurang baik dengan menggunakan perasaan. Sehingga lakilaki mudah memberikan sesuatu penilaian dan pemenuhan kebutuhan spiritual dengan baik, daripada perempuan yang cenderung memerlukan banyak pertimbangan dalam memberikan penilaian.

Hasil penelitian ini menunjukan bahwa karakteristik dengan usia tua lebih banyak yaitu sebesar $42(59,2 \%)$. Hasil uji chi-square menunjukan bahwa tidak ada hubungan antara usia perawat dengan pemenuhan kebutuhan layanan spiritual dengan nilai ( $\mathrm{p}$ value $=0,132)$. Hasil penelitian ini sejalan dengan hasil penelitian yang dilakukan oleh Sukma (2014) yang menyatakan bahwa tidak ada hubungan antara usia perawat dengan disiplin kerja perawat terhadap kebutuhan spiritual pasien. Usia tidak mempengaruhi tanggung jawab seseorang terhadap pekerjaannya. Hal ini bisa terjadi juga bahwa usia lebih tua memiliki tingkat kemangkiran yang tidak dapat dihindarkan, sehubungan dengan tingkat kesehatan dan kondisi fisik yang menurun, serta dalam sering didapatkan usia ini mereka sering meninggalkan tanggung jawab atas pekerjaannya dikarenakan makin kebutuhan yang dipenuhi diluar jam kerja (Ilyas, 2002).

Hasil penelitian ini menunjukan bahwa karaktertistik dengan tingkat pendidikan paling banyak yaitu S1/lebih tinggi sebesar 39 (54,9\%). Hasil analisis uji chi-square menunjukan bahwa ada hubungan antara tingkat pendidikan dengan pemenuhan kebutuhan layanan spiritual dengan nilai ( $p$ value $=0,039$ ). Sejalan dengan hasil penelitian yang dilakukan oleh Suni, dkk (2013) yang menyatakan bahwa ada hubungan antara tingkat pendidikan perawat terhadap sikap perawat dalam pemenuhan kebutuhan layanan spiritual pasien. Pendidikan sangat mempengaruhi sikap perawat dalam pemenuhan kebutuhan layanan spiritual pasien. Perawat dengan penddikan lebih tinggi memiliki kepuasan kerja yang tinggi dan cenderung bersikap positif karena dilandasi rasa aktualisasi atau pengakuan (Siagian, 2011). Pendidikan tinggi umumnya membuat seseorang lebih mampu dan bersedia menerima tanggung jawab. Dengan pendidikan tinggi, perawat akan lebih mampu menganalisis dan mengidentifikasi masalah pasien, yang kemudian secara rasional dapat mempertimbangkan intervensi keperawatan yang tepat untuk mengatasi masalah-masalah pasien (Nursalam, 2011).

Hasil penelitian ini menunjukan bahwa karakteristik dengan lama kerja lama (> 4 tahun) lebih banyak yaitu sebesar 37 (52,1\%). Hasil analisis uji chi-square menunjukan bahwa ada hubungan antara lama kerja dengan pemenuhan kebutuhan layanan spiritual dengan nilai ( $\mathrm{p}$ value $=0,042$ ). Hasil ini sejalan dengan hasil penellitian yang dilakukan oleh Faizin dan Winarsih (2008) yang menyatakan bahwa ada 
hubungan antara lama kerja perawat dengan kinerja perawat untuk melakukan pemenuhan kebutuhan spiritual pasien. Semakin lama seseorang bekerja, maka keterampilan dan pengalamannya juga semakin meningkat (Robbins dan Judge, 2008).

Hasil analisis uji chi-square pada penelitian ini menunjukan bahwa ada hubungan antara kecerdasan spiritual perawat dengan pemenuhan kebutuhan layanan spiritual pasien dengan nilai $(\mathrm{p}$ value $=0,022)$. Sejalan dengan hasil penelitian yang dilakukan oleh Sugianto (2018) yang menyatakan bahwa ada hubungan antara kecerdasan spiritual perawat dengan pemenuhan kebutuhan layanan spiritual pasien oleh perawat di RS PKU Muhammadiyah Gamping. Didukung oleh penelitian yang dilakukan oleh Sary (2018) yang menyatakan bahwa ada hubungan antara kecerdasan spiritual perawat dengan pemenuhan kebutuhan layanan spiritual pasien di ruang rawat inap RSUK Jember.

Seseorang yang cerdas secara spiritual tidak hanya cerdas dalam hal pengetahuan, namun juga mempunyai tingkat kesadaran tinggi mengenai spiritualitas, sehingga dapat membuat perawat lebih sensitif, reaktif dan tanggap terhadap makna dan pengalaman hidupnya, dan dengan demikian perawat cenderung akan lebih mudah untuk mempunyai sikap positif terhadap penyediaan perawatan spiritual pada pasien (Chiang et al, 2015). Perawat yang memelihara spiritualitasnya dapat menemukan sumber-sumber internal untuk merawat pasien melalui kenyamanan dalam diri, lebih sensitive terhadap kebutuhan spiritual pasien, dan memiliki koping yang lebih efektif terhadap stress yang dihadapi dalam memberikan asuhan keperawatan (Rohman, 2009).

\section{KESIMPULAN}

Pada penelitian ini dapat disimpulkan bahwa gambaran pemenuhan kebutuhan layanan spiritual pasien rawat inap di RSUD Banten Tahun 2019 lebih banyak memiliki pemenuhan kebutuhan layanan spiritual kurang baik. Hasil uji chi-square menunjukan bahwa variabel yang berhubungan dengan pemenuhan kebutuhan layanan spiritual yaitu tingkat pendidikan, lama kerja, dan kecerdasan spiritual perawat. Sedangkan variabel yang tidak berhubungan dengan pemenuhan kebutuhan layanan spiritual yaitu karakteristik jenis kelamin dan usia perawat. Adapun saran dari penelitian ini yaitu perlu adanya pendampingan khusus kepada perawat junior atau perlu adanya mentor dari perawat senior ke perawat junior yang memiliki lama kerja baru ( $\leq 4$ tahun) agar dapat dilatih dan dapat meningkatkan pengetahuan terkait perawatan spiritual, dan dapat meningkatkan perawatan spiritual yang lebih optimal.

\section{DAFTAR PUSTAKA}

Alfiannur, F., Nauli, F.A., \& Deei, A.P. (2015). Hubungan Antara Kecerdasan Spiritual dengan Tingkat Kecemasan Pasien Gagal Ginjal Kronik yang Menjalani Hemodialisa. JOM 2 (2).

Chiang, Y., Lee, H., \& Chu, T. (2015). The impact of nurse's spiritual health on their attitudes toward spiritual care, profesional, commitment, and caring. Nursing outlook, 1 10.

Ilyas, Y. (2002). Kinerja: Teori, Penilaian dan Penelitian Cetakan Ketiga. Depok: UI.

Merianti, L \& Andhika, S.L. (2016). Kecerdasan Spiritual Perawat dalam melaksanakan Kompetensi Perawat Melakukan Asuhan Spiritual Kepada Pasien Rumah sakit Islam Ibnu sina Yarsi Pada Panjang Tahun 2015. 'Afiyah 3 (1): 60-68. Program Studi Stikes Keperawatan Stikes Yarsi Sumbar Bukit Tinggi.

Nursalam. (2011). Manajemen keperawatan. aplikasi dalam praktik keperawatan profesional. Jakarta: Sagung Seto.

Potter, \& Perry. (2009). Fundamental of Nursing Fundamental Keperawatan. Jakarta: Salemba Medika.

Potter, \& Perry. (2005). Buku Ajar Fundamental Keperawatan. Jakarta: EGC

Primeilani. (2004). Gambaran Tingkat kedisplinan Pegawai Non Medis di Unit MSDM RS X Jakarta. Skripsi: UI.

Robbins, S., \& Judge, T. (2008). Perilaku organisasi. Jakarta: Salemba.

Rohman. (2009). Faktor-faktor yang berhubungan dengan pemberian asuhan spiritual oleh perawat di RS. Islam Jakarta. Magister Universitas Indonesia.

Sary, S. P. (2018). Hubungan Kecerdasan Spiritual Perawat dengan Pemenuhan Kebutuhan Spiritual Pasien di Rumah Sakit Umum Kaliwates Jember. Skripsi Universitas Jember.

Siagian, S. (2002). Kiat Meningkatkan Produktivitas Kerja. Jakarta: Rineka Cipta.

Sidabutar, R.R. (2016). Hubungan Penerapan Aspek spiritualitas Oleh Perawat dengan Pemenuhan Kebutuhan Spiritual pada Pasien Rawat Inap di RS. Islam Malahayati Medan. Jurnal Keperawatan Flora IX (1).

Sukma, M. S. (2014). Hubungan Motivasi Kerja dan 
184 Nurherawati, Emma Rachmawati, Mouhamad Bigwanto Hubungan Karakteristik dan Kecerdasan Spiritual...

Karakteristik Perawat dengan Disiplin Kerja Perawat di Ruang Rawat Inap Kelas III RSUD Pasar Rebo Tahun 2014. Skripsi: UIN Syarif Hidayatullah Jakarta.

Sumijatun. (2010). Konsep Dasar Menuju Keperawatan Professional. Jakarta: Transinfo Media.

Suni, A., Umanailo, D., \& Dabi, R. D. (2013). Pengetahuan dan Motivasi dengan Sikap Perawat dalam Pemenuhan Kebutuhan Spiritual Pasien di Ruang Rawat Inap RSUD dr. H. Chasan Boesoirie Ternate Tahun 2013. 